\title{
Knowledge and Misconceptions Regarding SLE among Medical Students at King Abdulaziz University
}

\author{
Yasser M. Bawazir ${ }^{* *}$ D, Ibtisam Jali²
}

${ }^{1}$ Assistant Professor of Medicine and Rheumatology, Department of Medicine, King Abdulaziz University, Jeddah, Saudi Arabia.
${ }^{2}$ Associate Professor of Medicine and Rheumatology, Department of Medicine, King Abdulaziz University, Jeddah, Saudi Arabia.
${ }^{*}$ Correspondence to: Yasser M. Bawazir (E-mail: ymbawazir@kau.edu.sa)
(Submitted: 12 May 2021 - Revised version received:02 June 2021 - Accepted: 23 June 2021 - Published online: 26 August 2021)

\begin{abstract}
Introduction Systemic lupus erythematosus (SLE) is a chronic autoimmune disorder that requires a multidisciplinary approach. The aim of this study was to assess the knowledge and misconceptions regarding SLE in sixth-year medical students in order to verify their understanding of the general aspects of SLE and provide recommendations to improve their learning experience.

Methods We created a two-part 25-item questionnaire of 25 questions to assess students' knowledge about epidemiology, clinical manifestations, complications, management, and prognosis of SLE, preferred ways of learning, and opinion on which specialties should include learning about the disease. The questionnaire was distributed to the participants through Google Forms.

Results A total of 200 students from King Abdulaziz University responded to the questionnaire. The prevalence of adequate knowledge among students was 39.5\%. There was a significant statistical difference between students with adequate knowledge and those without adequate knowledge according to the number of cases seen during training. There was a higher prevalence of adequate knowledge among female students and those who had a family history of SLE. Most students answered correctly the basic questions about SLE, while there were weak points in the questions about epidemiology and clinical manifestations. The preferred way of learning about SLE indicated by most respondents was to see patients in the wards and analyze the pathophysiology, diagnosis, and treatment of the disease. Most students chose internal medicine and rheumatology as specialties that should include learning about SLE.

Conclusion The findings reflect the need to improve the teaching of chronic medical diseases treated on an outpatient basis and to modify the medical school curriculum so as to prepare future physicians to deal with such cases.

Keywords Systemic lupus erythematous, medical students, medical education, SLE awareness, Saudi Arabia
\end{abstract}

\section{Introduction}

Systemic lupus erythematosus (SLE) is a chronic autoimmune disease that affects multiple organs and predominantly affects women. This heterogeneous condition has a wide spectrum of clinical manifestations related to drug reactions, associated comorbidities, and the disease itself. ${ }^{1}$ The diagnosis of SLE is challenging because of the heterogenicity of clinical manifestations and, in some cases, the presentation is quite severe, requiring prompt diagnosis and early immunosuppressive treatment.

Worldwide, the incidence of SLE is 23.2 per 100.000 people per year, while the highest incidence is seen in North America (241 per 100.000 people per year) and the lower incidences are recorded in African countries (0.3 per 100,000 people per year). The disease is mostly prevalent among women, regardless of age and ethnicity. ${ }^{3}$ These data are similar to those reported in Saudi Arabia, where the estimated prevalence of SLE is 19.28 per 100.000 people. ${ }^{4}$

Being a complex disease, SLE requires a multidisciplinary approach, including rheumatology, dermatology, cardiology, pulmonology, and nephrology. Assessing the disease can help identify defects in its treatment. Kerezoudis et al., ${ }^{5}$ conducted a study with 260 students - 114 in preclinical and 146 in clinical years - at two medical schools to assess the depth of their knowledge using survey assessment. They identified several misconceptions in the perception of SLE and attributed this to the lack of clinical practice and the low number of patients. ${ }^{5}$

Rheumatology curriculum in our intuition includes lectures, clinical based learning sessions and clinical examination sessions. All sixth-year students must undergo a week of intense rheumatology course, at the completion of this week, assessment takes place. The total number of the sixth-year students (final clinical year) is around 350 students.

Given the magnitude of this disease, this study aimed to assess the knowledge and misconceptions regarding SLE in sixth-year medical students in order to verify their understanding of the general aspects of SLE and obtain feedback on their curriculum and learning experience. To this end, a 25-item questionnaire was administered to sixth-year medical students at the Faculty of Medicine at King Abdulaziz University. Based on the questionnaire results, suggestions and recommendations were made to improve the learning experience about SLE at the referred university.

\section{Methods \\ Participants}

Participants in this study were sixth-year medical students at the Faculty of Medicine at King Abdulaziz University. The medicine program at King Abdulaziz University comprises six years, the first three years being preclinical and the last three years clinical. In particular, the sixth year includes medical subspecialties, such as rheumatology. Thus, the inclusion criterion for this study was to be in the sixth year of the medicine program, since having obtained specific knowledge related to SLE was mandatory to answer the study questionnaire. The questionnaire was distributed to 350 medical students.

\section{Study Design}

This was an observational cross-sectional study in which a 25-item two-part questionnaire was structured using Google 
Forms. The first part included 19 questions and aimed to assess students' knowledge about epidemiology, clinical manifestations, complications, management, and prognosis of SLE. If the participant answer 13 out of 19 questions correctly he will be considered as having adequate knowledge. The second part included six questions and aimed to obtain general information about the participants, their preferred ways of learning about SLE, and their opinion on which specialties should include learning about SLE, as well as how many cases of SLE are seen during their training. The questionnaire was conducted in English, which is the language of instruction at the Faculty of Medicine at King Abdulaziz University.

For the development of the questionnaire items, we conducted a search on PubMed and Google Scholar for validated SLE-related questionnaires. As a result, we identified only two non-validated questionnaires to assess knowledge of SLE among medical students. Therefore, we developed questions to assess the fundamentals of SLE based on the King Abdulaziz university curriculum.

\section{Study Procedure}

The questionnaire developed using Google Forms was distributed to medical students by e-mail on the day of completion of the rheumatology rotation assessment. The respondents were allowed to submit the form only once. Since participation was optional, only 200 of the 350 medical students agreed to participate. All fourth- and fifth-year students were excluded from the study as they don't rotate in rheumatology. The study did not require ethical approval as per the department of bioethics in our institution.

\section{Statistical Analysis}

Data were analyzed using the Statistical Package for the Social Sciences (SPSS), version 21 (IBM Inc., Armonk, NY, USA). Categorical variables were presented as numbers and precents and were compared using Chi-square test. Continuous variables were non normally distributed, so presented as median and range (minimum-maximum) and were compared using Mann Whitney $U$ test. All tests were 2 -tailed, and a $P$ value $<0.05$ was considered statistically significant.

\section{Results}

Table 1 shows the demographic characteristics of the participants. Of the 200 respondents, 198 (99\%) were 18 to 25 years old and 117 (58.5\%) were women. More than half (107, 53.5\%) saw only one to three cases of SLE during training and $30(15 \%)$ had a family history of SLE.
Table 2 shows the prevalence of adequate knowledge about SLE among the study participants. In order for respondents' knowledge about SLE to be assessed as adequate, 13 of the 19 questions in the first part of the questionnaire must be answered correctly. The prevalence of adequate knowledge about SLE among the study participants was 39.5\%.

There was a significant statistical difference between students with adequate knowledge and students without adequate knowledge according to the number of cases seen during training $(P<0.001)$. As shown in Table 3 , as the number of

\begin{tabular}{lcc}
\hline \multicolumn{3}{l}{ Table 1. Demographic characteristics of the participants $(\boldsymbol{n}=\mathbf{2 0 0})$} \\
\hline Variable & $\begin{array}{c}\text { Number of } \\
\text { participants }\end{array}$ & $\begin{array}{c}\text { Percentage of } \\
\text { participants }\end{array}$ \\
\hline Gender & 83 & 41.5 \\
Male & 117 & 58.5 \\
Female & & \\
Age & 2 & 1.0 \\
$\quad<18$ years old & 198 & 99.0 \\
18-25 years old & \\
Number of cases seen during training & 27.5 \\
0 & 55 & 53.5 \\
1-3 & 107 & 15.5 \\
$4-9$ & 31 & 3.5 \\
$>10$ & 7 & \\
Family history of SLE & & 2.0 \\
Maybe & 4 & 83.0 \\
No & 166 & 15.0 \\
Yes & 30 &
\end{tabular}

Note. All variables are summarized in numbers and percentages.

Table 2. Prevalence of adequate knowledge about SLE among participants $(n=200)$

\begin{tabular}{lcc}
\hline Variable & $\begin{array}{c}\text { Number of } \\
\text { participants }\end{array}$ & $\begin{array}{c}\text { Percentage of } \\
\text { participants }\end{array}$ \\
\hline $\begin{array}{l}\text { With adequate } \\
\text { knowledge }\end{array}$ & 79 & 39.5 \\
$\begin{array}{l}\text { Without } \\
\text { adequate } \\
\text { knowledge }\end{array}$ & 121 & 60.5 \\
Total & 200 & 100.0 \\
\hline
\end{tabular}

Note. All variables are summarized in numbers and percentages.

\section{Table 3. Prevalence of adequate knowledge about SLE according to number of cases seen during training}

\begin{tabular}{|c|c|c|c|c|c|c|}
\hline \multirow{3}{*}{ Variable } & & \multicolumn{4}{|c|}{ Adequate knowledge } & \multirow{3}{*}{$P$-value } \\
\hline & & \multicolumn{2}{|c|}{ Yes } & \multicolumn{2}{|c|}{ No } & \\
\hline & & Number & $\%$ & Number & $\%$ & \\
\hline \multirow{4}{*}{$\begin{array}{l}\text { Number of cases seen } \\
\text { during training }\end{array}$} & 0 & 6 & $11 \%$ & 49 & $89 \%$ & \multirow[t]{4}{*}{$<0.001$} \\
\hline & $1-3$ & 44 & $41 \%$ & 63 & $59 \%$ & \\
\hline & $4-9$ & 22 & $71 \%$ & 9 & $29 \%$ & \\
\hline & $>10$ & 7 & $100 \%$ & 0 & $0 \%$ & \\
\hline Total & & 79 & $39.5 \%$ & 121 & $60.5 \%$ & \\
\hline
\end{tabular}

Note. All variables are summarized in numbers and percentages. 
cases increases, the prevalence of adequate knowledge also increases. According to Table 3, all students who saw more than 10 cases during training had adequate knowledge. The test of significance was carried out at the 0.05 level. A chisquare test was used to assess the statistical significance of the differences between the two groups according to the number of cases seen during training.

Regarding the relationship between prevalence of adequate knowledge and gender/family history of SLE, a statistically significant $(P<0.001)$ higher percentage of adequate knowledge was identified among female respondents and those with a family history of SLE (Table 4). The prevalence of adequate knowledge about SLE was higher among women (56\%) and among students with a family history of SLE (70\%). The test of significance was carried out at the 0.05 level. A chi-square test was used to assess the statistical significance of the differences between the two groups according to gender and family history of SLE.

The analysis of the first part of the questionnaire (19 questions) revealed that the majority of students answered correctly the basic questions about SLE. On the other hand, there were weak points in the questions about epidemiology and clinical manifestations (Figure 1).

As for the second part of the questionnaire, question 24 asked students to choose their preferred ways of learning about SLE. More than one choice was allowed. The preferred way of learning about SLE indicated by most respondents was to see patients in the wards and analyze the pathophysiology, diagnosis, and treatment of the disease (172 responses), followed by seeing a patient-actor with SLE during class and discussing symptoms, diagnosis, differential diagnosis, and treatment (77 responses). Watching educational videos with real patients and discussing clinical vignettes during lectures obtained 72 and 63 responses, respectively (Table 5).

Finally, the questionnaire asked students their opinion on which medical school specialties should include learning about SLE. More than one choice was allowed. Most students choose internal medicine (130) and rheumatology (127), while 86 choose pathology (Table 6).

\section{Discussion}

Advances in medicine in recent decades have been accompanied by a marked increase in the number of chronic diseases worldwide. Such diseases have been managed mainly in the outpatient clinic sitting. Medical education in most medical schools follows the Flexner model, which focuses mainly on inpatient hospital-based training. The problem with this model is that it does not focus on the outpatient training sitting. ${ }^{6}$ The main barriers to outpatient education are the lack

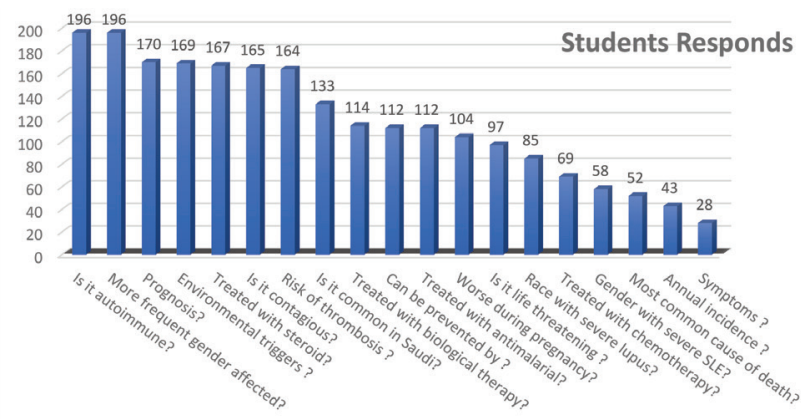

Fig. 1 Frequency of correct answers in each of the 19 questions about SLE in descending order.

\begin{tabular}{lc}
\hline $\begin{array}{l}\text { Table 5. Frequency of preferred ways of learning about SLE } \\
\text { among participants }\end{array}$ & \\
\hline Ways of learning about SLE & Number of responses (\%) \\
\hline $\begin{array}{l}\text { A. See patients in the wards and analyze } \\
\text { the pathophysiology, diagnosis, and }\end{array}$ & $172(44.7 \%)$ \\
treatment of the disease. & $77(20 \%)$ \\
$\begin{array}{l}\text { B. See a patient-actor with SLE during } \\
\text { class and discuss symptoms, diagnosis, }\end{array}$ \\
$\begin{array}{l}\text { differential diagnosis, and treatment. } \\
\text { C. Watch educational videos with real } \\
\text { patients. }\end{array}$ \\
$\begin{array}{l}\text { D. Discuss clinical vignettes during } \\
\text { lectures. }\end{array}$ \\
\begin{tabular}{l} 
Total \\
\hline
\end{tabular}
\end{tabular}

Note. All variables are summarized in numbers.

\begin{tabular}{lc}
$\begin{array}{l}\text { Table 6. Specialties that should include learning about SLE in } \\
\text { the opinion of the participants }\end{array}$ \\
\hline Specialty & Number of responses (\%) \\
\hline Internal medicine & $130(32.7 \%)$ \\
Rheumatology & $127(31.9 \%)$ \\
Pathology & $86(21.6 \%)$ \\
Physiology & $34(8.5 \%)$ \\
Biology & $20(5 \%)$ \\
Total & $397(100 \%)$ \\
\hline
\end{tabular}

Note. All variables are summarized in numbers.

Table 4. Prevalence of adequate knowledge about SLE according to gender and family history of SLE

\begin{tabular}{|c|c|c|c|c|c|c|}
\hline \multirow{3}{*}{ Variable } & & \multicolumn{4}{|c|}{ Adequate knowledge } & \multirow{3}{*}{$P$-value } \\
\hline & & \multicolumn{2}{|c|}{ Yes } & \multicolumn{2}{|c|}{ No } & \\
\hline & & Number & $\%$ & Number & $\%$ & \\
\hline \multirow[t]{2}{*}{ Gender } & Male & 13 & $16 \%$ & 70 & $84 \%$ & $<0.001$ \\
\hline & Female & 66 & $56 \%$ & 51 & $44 \%$ & \\
\hline \multirow[t]{3}{*}{ Family history of SLE } & Maybe & 0 & $0 \%$ & 4 & $100 \%$ & $<0.001$ \\
\hline & No & 58 & $35 \%$ & 108 & $65 \%$ & \\
\hline & Yes & 21 & $70 \%$ & 9 & $30 \%$ & \\
\hline
\end{tabular}

Note. All variables are summarized in numbers and percentages. 
of evidence in the literature, conflicts between medical education and healthcare, and inadequate financial incentives for academic medical staff. ${ }^{7}$ SLE is a systemic disease treated mainly in the outpatient sitting, whereas few complicated cases are hospitalized. ${ }^{8}$ This may contribute to students' lack of exposure to patients with chronic illnesses. At King Abdulaziz University, students must complete three years of preclinical studies before beginning the three clinical years. Clinical teaching in the medicine program is based mainly on inpatient teaching, with limited outpatient exposure. ${ }^{8}$

Unfortunately, only $39.5 \%$ of the respondents in this study showed adequate knowledge about SLE. We attribute this result to the number of cases seen during clinical practice, as most respondents saw only one to three cases. Women showed to be more knowledgeable about SLE, which could be attributed to the higher prevalence of the disease among women. ${ }^{1,3}$ In addition, students with a family history of SLE showed more adequate knowledge. This may be due to the fact that these students sought to educate themselves more about the disease, as the risk of developing SLE are higher among relatives of patients with SLE.

To suggest alternatives to improve the teaching of rheumatology, which is a critical specialty in the treatment of SLE, we analyzed the weak points in the questionnaire responses. We found that there is little awareness among students about the current use of chemotherapy and biological therapy in patients with SLE. This is clearly explained by the low number of cases seen during training, in addition to the majority of assistance to stable patients at the outpatient clinic. Furthermore, at the university hospital, chemotherapy and biological therapy is administered at the day care unit, and students do not rotate through this unit. Unlike rheumatoid arthritis, for which we have many approved biologic therapies, ${ }^{9}$ for SLE, we currently have belimumab approved for treatment. ${ }^{10}$ Other agents such as ustekinumab, ${ }^{11}$ anifrolumab, ${ }^{12}$ and Janus kinase inhibitors, ${ }^{13}$ are still to be approved.

Almost half of the respondents were not aware of the worsening of SLE during pregnancy. Since pregnancy with SLE is high risk, the disease must be stable before conception. Risks include SLE flare and the neonatal lupus. Although the prognosis for pregnant women has improved considerably, the fetal risk, although progressively reduced, is still higher in pregnancies of patients with SLE than in pregnancies of healthy women. Miscarriage, premature delivery, and preeclampsia, as well as heart problems in the baby, are the major complications that can occur. ${ }^{14}$ We believe that the respondents in this study are not adequately aware of the complications of pregnancy with SLE because the university does not have a special clinic for pregnant women with SLE in collaboration with obstetrics and the patients are followed in the regular SLE clinics, so that students do not have the opportunity to see such cases in the most appropriate way.

Almost half of the students responded that SLE is not life threatening, which is also attributed to the fact that they do not see many inpatient cases. Another important point is that high mortality is more observed in cases of circulatory diseases and infections ${ }^{15}$ rather than other SLE complications, and this usually happens when patients are hemodynamically unstable and are referred to intensive care units.

Given that SLE is more common in women ${ }^{1}$ (as mentioned earlier), there is an obvious misconception among students that the disease is more severe in women as well. In fact, the opposite is true: men with SLE are more likely than women to develop disabilities, hypertension, thrombosis, and renal, hematological, and serological manifestations. Men with SLE are also more likely than women to suffer end-organ damage, including neuropsychiatric, renal, cardiovascular, peripheral vascular diseases, and myocardial infarction. ${ }^{16}$

The students' preferred way of learning about SLE was to see patients in the wards and analyze the pathophysiology, diagnosis, and treatment of the disease, followed by seeing a patient-actor with SLE during class and discuss symptoms, diagnosis, differential diagnosis, and treatment. This result is in line with our opinion that students need to be exposed to more inpatient cases to improve their knowledge about this heterogeneous disease.

Finally, students indicated that they preferred to study SLE in internal medicine and rheumatology rotations rather than during the basic science years. Given that the integration of the clinical and basic years, students concentrate mainly on ways to obtain good grades rather than on how the knowledge acquired can be applied in clinical settings. Generally, students see learning as a process whereby knowledge is provided to them by the teacher and the curriculum as an aggregate of separate subjects (e.g., pathology and anatomy) rather than a single general topic (e.g., medicine).$^{17}$

Given the above considerations, we suggest the following changes to improve the learning experience regarding SLE for students at the Faculty of Medicine at King Abdulaziz University. First, at this university, rotation in rheumatology used to be merged with rotation in internal medicine. We suggest implementing a separate focused short rotation in rheumatology. Second, as we have observed during their busy clinical rotations, students rarely have the time to reflect on their basic science knowledge. For this reason, we suggest introducing clinical-based learning, in which the discussion starts with basic pathology and immunology and ends with clinical diagnosis and management, in the hope that some of the important basic information can be provided to senior medical students. Third, to improve students' awareness about the use of chemotherapy or biological therapy in patients with SLE, we suggest a time dedicated to patients admitted to the day care unit, as well as the acquisition of knowledge about the indications, dosage, and side effects of treatments. Finally, we recommend the creation of a rheumatology admission unit and collaboration in the clinic with colleagues from the obstetrics department for high-risk patients.

\section{Study Limitation}

This study assesses the knowledge of 6th year medical students at king Abdulaziz university. The major limitation of this study is the use of non-validated questionnaire which was designed by the authors. As with any survey-based studies, a selection and sampling bias and we overcome this by consulting statistician.

\section{Acknowledgments}

We would like to thank Editage (www.editage.com) for English language editing. 


\section{Funding}

This research received no specific grant from any funding agency in the public, commercial, or not-for-profit sectors.

\section{Declaration of Conflicting Interests}

The Authors declare that there is no conflict of interest.

\section{References}

1. Di Battista M, Marcucci E, Elefante E, et al. One year in review 2018: systemic lupus erythematosus. Clin Exp Rheumatol. 2018;36(5):763-777.

2. Sebastiani GD, Prevete I, Iuliano A, Minisola G. The importance of an early diagnosis in systemic lupus erythematosus. Isr Med Assoc J. 2016; 18(3-4):212-215.

3. Rees F, Doherty M, Grainge MJ, Lanyon P, Zhang W. The worldwide incidence and prevalence of systemic lupus erythematosus: a systematic review of epidemiological studies. Rheumatology (Oxford). 2017:56(11):1945-1961

4. Al-Arfaj AS, Al-Balla SR, Al-Dalaan AN, et al. Prevalence of systemic lupus erythematosus in central Saudi Arabia. Saudi Med J. 2002;23(1):87-89.

5. Kerezoudis $P$, Lontos $K$, Apostolopoulou A, et al. Lupus in medical education: student awareness of basic, clinical, and interdisciplinary aspects of complex diseases. J Contemp Med Educ. 2016;4(3):97-106.

6. Emanuel EJ. Reforming American medical education. Milbank Q. 2017:95(4):692-697.

7. Oliveira Franco RL, Martins Machado JL, Satovschi Grinbaum R, Martiniano Porfírio GJ. Barriers to outpatient education for medical students: a narrative review. Int J Med Educ. 2019;10:180-190.

8. Sims GN, Jr., Smith HR. Outpatient management of systemic lupus erythematosus. Cleve Clin J Med. 1996;63(2):94-100. doi: 10.1097/ BOR.0000000000000480

9. Smolen JS, Landewé RBM, Bijlsma JWJ, et al. EULAR recommendations for the management of rheumatoid arthritis with synthetic and biological disease-modifying antirheumatic drugs: 2019 update. Ann Rheum Dis. 2019;79(6):685-699. doi: 10.1136/annrheumdis-2019-216655

10. Fanouriakis A, Kostopoulou M, Alunno A, et al. 2019 update of the EULAR recommendations for the management of systemic lupus erythematosus. Ann Rheum Dis. 2019;78(6):736-745. doi: 10.1136/ annrheumdis-2019-215089

11. Costedoat-Chalumeau N, Houssiau FA. Ustekinumab: a promising new drug for SLE? Lancet. 2018;392(10155):1284-1286. doi: 10.1016/S01406736(18)32330-4

12. Morand EF, Furie $R$, Tanaka IN, et al. Trial of anifrolumab in active systemic lupus erythematosus. N Engl J Med. 2020;382(3):211-221. doi: 10.1056/ NEJMoa1912196

13. Mok CC. The Jakinibs in systemic lupus erythematosus: progress and prospects. Expert Opin Investig Drugs. 2019;28(1):85-92. doi: $10.1080 / 13543784.2019 .1551358$

14. Moroni G, Ponticelli C. Pregnancy in women with systemic lupus erythematosus (SLE). Eur J Intern Med. 2016;32:7-12. doi: 10.1016/j. ejim.2016.04.005

15. Bernatsky S, Boivin J-F, Joseph L, et al. Mortality in systemic lupus erythematosus. Arthritis Rheum. 2006;54(8):2550-2557. doi: 10.1002/ art.21955

16. Tan TC, Fang H, Magder LS, Petri M. Differences between male and female systemic lupus erythematosus in a multiethnic population. J Rheumatol. 2012:39(4):759-769. doi: 10.3899/jrheum.111061

17. Alam A. How do medical students in their clinical years perceive basic sciences courses at King Saud University? Ann Saudi Med. 2011;31(1):58-61. doi: $10.4103 / 0256-4947.75780$ 